\title{
Functional Diversity: An Important Measure of Ecosystem Functioning
}

\author{
Madhurankhi Goswami¹, Purnita Bhattacharyya ${ }^{1}$, Indranil Mukherjee², Prosun Tribedi ${ }^{*}$ \\ ${ }^{1}$ Department of Microbiology, Assam Don Bosco University, Guwahati, India \\ ${ }^{2}$ Department of Natural Science \& Centre of Excellence in Environmental Technology \& Management, Maulana Abul Kalam Azad \\ University of Technology, Kolkata, India \\ Email: madhurankhigoswami@yahoo.com,purnitabhattacharyya@gmail.com,indranil.m11@gmail.com, ^tribedi.prosun@gmail.com
}

How to cite this paper: Goswami, M., Bhattacharyya, P., Mukherjee, I. and Tribedi, P. (2017) Functional Diversity: An Important Measure of Ecosystem Functioning. Advances in Microbiology, 7, 82-93. http://dx.doi.org/10.4236/aim.2017.71007

Received: December 29, 2016

Accepted: January 17, 2017

Published: January 20, 2017

Copyright (C) 2017 by authors and Scientific Research Publishing Inc. This work is licensed under the Creative Commons Attribution International License (CC BY 4.0).

http://creativecommons.org/licenses/by/4.0/

cc (i) Open Access

\begin{abstract}
Functional diversity is a component of biodiversity that generally covers the range of functional traits of microorganisms prevailing in an ecosystem. Functional diversity is of high ecological importance because it is capable of influencing several aspects of ecosystem functioning like ecosystem dynamics, stability, nutrient availability, etc. Functional diversity of a community can be measured by functional richness and evenness. Functional richness refers to the number of species inhabiting a particular niche and functional evenness reveals how evenly the species are being distributed. Increase or decrease in functional richness and evenness simultaneously increases and decreases the functional diversity respectively. Decrease in functional richness and evenness decreases the ecosystem productivity and stability which ultimately decreases functional diversity of the same ecosystem. The effects of functional diversity on the productivity of an ecosystem can be quantitatively explained by the sampling effect model and the niche differentiation model. There are other proposed mechanisms like Niche complementarity and species redundancy relating functional diversity with ecosystem functioning. Rivets and idiosyncratic models relate functional diversity and species richness with ecosystem functioning. By considering the above proposed models on ecosystem functioning, it can be considered that functional diversity is a principal component of ecosystem functioning. So it can be assumed that, knowledge about a particular ecosystem reveals its richness and evenness which enable an individual knowing about the diversity of functional traits prevailing in the ecosystem. Thus, it opens up a new way in understanding and carrying out ecology related studies more efficiently and precisely in ecosystem.
\end{abstract}

\section{Keywords}

Functional Diversity, Species Richness, Species Evenness, Ecosystem Productivity, Ecosystem Functioning 


\section{Introduction}

Ecosystem represents a complex balanced interaction between the two important components, biotic and abiotic that constitutes a healthy ecosystem. Minute changes in either of the two components will bring about considerable changes in the ecosystem dynamics. Initially efforts were made to determine the efficiency of an ecosystem by taking into account species richness which was considered as the principle index of biodiversity. An ecosystem with high biodiversity is capable of developing into an efficient ecosystem. In contrast to this, a wide array of studies reveals that it is the functional traits of the organisms and not their taxonomic identification that affects the ecosystem linked processes [1]. Thus, in order to undertake mechanistic studies of ecosystem dynamics, it is the functional diversity that happens to be the most significant or crucial index for addressing the efficiency determination of an ecosystem. Functional diversity is a component of biodiversity that generally includes the wide range of metabolic activities carried out by the microorganisms in communities and ecosystem. It can be taken as a measure for distribution and productivity of organisms inhabiting a particular niche [1] [2]. Functional diversity is of high ecological importance because it is one of the components of diversity that influences the ecosystem dynamics, stability, nutrient availability, productivity and other aspects of ecosystem functioning [3]. The functional diversity indicates the reliability of an ecosystem by addressing their diverse metabolic potential.

Soil harbours a wide diversity of microbial communities, but since soil is heterogeneous in nature and a discontinuous system, the soil microbial communities are not regularly distributed, rather they are present in discrete microhabitats [4] [5]. The environmental factors like carbon and other energy sources, available water, ionic balance, temperature, $\mathrm{pH}$ and intra- and inter-species microbial interactions affect the microbial population dynamics and their activity considerably [6] [7] [8]. Therefore, each microbial niche happens to be ubiquitous in terms of their microbial community structure [6]. This ubiquitous nature of the microbial niches results in the variation of the ecosystem efficiency. Therefore, screening of an efficient soil ecosystem happens to be important for diverse applications. Therefore, in the current study, we have explored the potentiality of microbial functional diversity to be an important indicator for the selection of efficient ecosystem.

\section{Measure of Functional Diversity}

Functional diversity of a community can be measured through measurement of traits usually with the help of two indices [9] [10] - functional richness and functional evenness [11]. Two important aspects of these indices are-firstly, they are independent of each other and secondly, both the components relate to the same entity [9].

1) Functional richness refers to the amount of a particular ecological niche occupied by the species within a community. It is generally used as an indicator for potentially used and unused niche space [9]. However, two communities with the same number of species may have different functional richness when functional traits of species are more closely clustered in one community than in the other [12]. Low functional richness reduces productivity of ecosystem [13] because low functional richness indi- 
cates that some of the potentially available resources are being unused as the variation of species occupying a particular niche is lower and hence is incapable of utilising the entire available resources.

Initially individual characters are taken into account in determining whether any particular character is related to ecosystem functioning but later multiple characters were considered. Measurement of each character from several individuals of each species is required to describe the distribution. For example-if the functional character represents environmental tolerance, lower functional richness implies that under a stressed environmental condition the possibility of the species to take the advantage of the conditions will be missing thus reducing buffering against environmental fluctuations [14]. Species richness and functional richness are inherently linked. Monocultures fall into one functional group representing a single functional trait whereas polycultures are usually sampled from a pool of species representing multiple functional traits, therefore, the correlation between species richness and functional richness theoretically ranges from negligible to a one-to-one relationship [15]. Increase in species richness depends on many factors like nutrient availability, light and temperature availability, water levels, etc. Kleinebecker, Hoelzel and Vogel [16] found that the availability of desirable nutrients in an ecosystem affects species richness. Functionally diverse communities were prone to composition shifts and increased dominance with nutrient addition because the diverse microbial community might contain a species with functional traits suited for exploitation of the added resource.

Light limitation can reduce species richness and species diversity, but the impact of it depends upon functional evenness of the species in the community i.e., light limitation can reduce species richness and diversity only if the microbial community consists of phototrophic cells in majority [17]. As environmental filters (such as light) act on functional traits, understanding the correspondence between abiotic factors and particular functional traits would help to predict which species from a regional pool could colonize and survive in the respective area [18]. Reductions in light or temperature restrict the viable growth habits, resulting in decrease of species richness [19]. Species richness linearly decreases with increase in water levels, which indicates that the water level have exceeded the optimum levels, that effects the growth of the microbial cells [20].

2) Functional evenness is a measure of the species trait distributed regularly within the occupied trait space. In other words, functional evenness can be referred to as the degree to which the biomass of a community is distributed in niche space to allow effective utilisation of the entire range of resources available in the particular ecosystem. Lower functional evenness indicates that some of the parts of the niche space are under utilisation which results in decrease in productivity and reliability of the desired ecosystem [9]. Functional homogeneity or evenness of a microbial population contributes extensively towards the development of a stable ecosystem. Functional traits if not evenly distributed, the traits are at a risk of being diluted from the ecosystem because the existed traits will face a tremendous competition. Two ecosystems with diverse evenness will exhibit altered or different functional traits after a particular time gap, even if both the ecosystems are of same size and exhibits the same quantity of functional richness. An ecosystem with high functional evenness indicates that the func- 
tional traits are evenly distributed in the particular ecosystem. So if some of the members with a particular trait in an ecosystem are lost in presence of some disturbances, then the existing member with the similar trait replaces the lost trait i.e., the lost member from the ecosystem and thus successfully retains its native state. In contrast to this, an ecosystem with uneven functional traits indicates that some of the functional traits in the ecosystem are distributed in high numbers whereas some in lesser numbers. Thus the selection pressure mounts considerably on those functional traits which are less in numbers. Therefore, due to certain disturbances in the ecosystem, if some of the members of a particular trait are deleted, it might result in complete rejection of the desired trait as it poses a difficulty in replacement of the missing number since they are very lesser in number.

\section{The Effects of Functional Diversity on Productivity}

Functional diversity is a measure of functional traits of an organism that influences one or more aspects of ecosystem functioning. In other words, it measures the distribution and productivity of organisms inhabiting a particular niche [1] [2]. But in spite of this, functional diversity has certain effects on the productivity of an ecosystem. These effects are qualitatively been described by two different models [3].

\subsection{Sampling Effect Model}

The first model is the sampling effect model that hypothesizes that species inhabiting a particular ecosystem differs from one another depending on their competitive ability. This statement infers that species that are highly competitive in an ecosystem are at the same time found to be more productive [3]. Thus sampling effect model is self explanatory in the fact that an ecosystem with more of competitive species will be more productive. A species is considered to be the best competitor among a group of competitors in an ecosystem if it utilizes the minimum of the limiting source in comparison with that of the others inhabiting the same ecosystem [21]. Sampling effect model also predicts that increase of diversity in an ecosystem also increases the productivity rate whereas decrease in diversity results in a decrease in productivity rate. In addition to this, the sampling model also elucidates that with increase in diversity there is increase in usage of unconsumed resource. Thus it can be said that, functional diversity can be directly related to ecosystem productivity and indirectly to the unconsumed resource i.e. increase in functional diversity increases the ecosystem productivity whereas decreases the amount of unconsumed resource. Suppose if we want to increase the soil fertility by introducing nitrogen, we need to add nitrogen fixing bacteria to that soil. These nitrogen fixing bacteria, if they are highly competitive, they can tolerate the competition for the resource with the existing microorganism. If they survive, they can execute the biological process of nitrogen fixation in the soil which will result in overall increase in nitrogen content of the soil. If the newly introduced organism is being killed due to the high competition with the existing organism, then the overall functional diversity as well as the ecosystem productivity will not be increased. If the latter organism survives with that of the existing ones by adjusting the competition, then the overall functional diversity as well as ecosystem productivity increases. 


\subsection{Niche Differentiation Model}

Niche differentiation model assumes that a habitat is spatially or temporally heterogeneous or diverse. That is the species residing in that particular habitat exhibit diverse traits which ultimately determines their response to this heterogeneity. The Niche differentiation model also assumes that each species residing in a particular habitat is a superior competitor and is capable of resisting high competition, which ultimately designates it to be more productive. In accordance with the niche differentiation model, each species should possess selective combination of traits such as high soil $\mathrm{pH}$ and temperature tolerance which will allow an organism to potentially exploit the available resources under the prevailing conditions and results to be a good competitor in some definite part of the habitat rather exploiting the entire range of conditions prevailing all throughout the habitat. This selective exploitation of resources by a particular organism differentiates the macro habitats into several micro habitats enabling abundance of an organism in their respective occupied microhabitat. Thus each species will be a good competitor in their definite micro habitats and due to the high competition the abundances of the overlapping species will be reduced.

In order for proper utilisation of soil insoluble phosphorus by the plants, phosphate solubilising bacteria needs to be introduced into the soil. These are a group of bacteria that exhibit a combination of traits like solubilisation of insoluble phosphate and at the same time secretion of high amounts of organic acids. These traits enable them to be a good competitor in a phosphorus rich microhabitat. A superior competitor can always survive the high competition in a desired microhabitat because it posses the traits that are required for its survival. As each species is a superior competitor in its own desired microhabitat, so the traits existing in the particular habitat are significantly diverse. The existence of diverse traits in a particular ecosystem will automatically increase its productivity rate. So it can be said that the Niche differentiation model positively correlates functional traits with the productivity of an ecosystem.

\section{Effects of Functional Diversity on Ecosystem Functioning}

Functional diversity is a measuring index that is used to measure the reliability as well as the proper functioning of the ecosystem [22] [23] [24] [25] [26]. A linear response of increasing function with increasing diversity indicates that all species, even rare ones, are required to maintain healthy levels of ecosystem function. Alterations in the functional diversity of an ecological niche space has certain effects on the ecosystem functioning. There are several proposed mechanisms behind the diversity and ecosystem function relationships. These mechanisms are based on the patterns of species distribution in niche or functional space.

\subsection{Niche Complementarity Model}

Niche complementarity has been proposed as a mechanism linking diversity with ecosystem processes [13] [27] [28]. The word niche refers to a set of species that have similar traits and are likely to be similar in their effects on ecosystem functioning [3]. On the other hand, complementarity in ecology refers to the niche partitioning or differences in resource requirements among species [29] [30]. Niche complementarity 
hypothesis implies that functional groups, occupies functionally distinct niches in an ecosystem and use resources in a complementary way. That is, if some of the functional groups inhabiting a particular niche go extinct, the resource exploitation will decrease resulting in declining of ecosystem functions [31]. In order to draw a positive relationship between functional diversity and ecosystem productivity on the basis of niche complementarity hypothesis, different grasslands harbouring different functional groups using different nitrogen sources was considered. Different forms of nitrogen acquisition such as symbiotic nitrogen fixation, internal nitrogen recycling or soil nitrogen uptake have been studied for different functional groups in grasslands, suggesting complementarity nitrogen strategies [32] [33] [34]. For example, suppose a fertile land harbours a wide variety of microorganisms. The resources available in that particular niche space is completely being utilised by the existing species for the purpose of nutrition or for the conversion of complex insoluble substances to simpler soluble ones to be utilised by other microorganisms. If there is deletion or removal of some of the microbial cells from the desired ecological niche space, decreasing the functional diversity, the rate and amount of utilisation of the available resources will decrease which will ultimately hamper the normal ecological balance of the soil resulting in lowering of the soil ecosystem functioning. Thus it can be referred that functional diversity has a distinct correlation with the ecosystem functioning.

\subsection{Species Redundancy Hypothesis}

The species redundancy hypothesis shows relationship between diversity and ecosystem functioning and also helps in understanding the ecological values of biodiversity [23] [24] [35] [36] [37] [38] [39]. The word redundancy refers to unnecessary. Walker introduced the concept for the purposes of assessing conservation priorities [23] [36] arguing that conservation efforts should focus on species that are singular in their contribution to ecosystem functioning. According to this hypothesis, the rate of ecosystem functions increases as more species are present. But this occurs only to certain extent after which more of the species are redundant and do not have any additional effect on ecosystem functioning. In this theory, the loss of species does not show any initial effect, but after certain point the ecosystem functions begin to suffer. For example, suppose an ecosystem harbours diverse microbial species. This diverse ecosystem shows high species richness but has less species evenness i.e., there is great diversity in the ecosystem with wide number of organisms but the organisms are not evenly distributed. Lack of evenness represents that the organisms differ greatly in their numbers in that ecosystem. In this context, if the microorganisms with highly important functional traits but lower in number, gets removed from the ecosystem instead of removal of the redundant species that are greater in numbers will in turn affect the ecosystem functioning. Thus it can be seen that if there is decrease in functional diversity there will be automatically decrease in ecosystem functioning.

\section{Effects of Species Richness and Functional Diversity on Ecosystem Functioning}

Darwin [40] for the first time proposed that an increase in functional diversity of an 
ecosystem also increases the ecosystem stability. This was reiterated by MacArthur [41], and modelled by May [42]. Ecologists have proposed that an increase in species richness also increases functional diversity, producing an increase in ecological stability [14]. There are many competing models but the two most common models describing the relation between species richness and functional diversity with ecosystem stability are as follows.

\subsection{Rivets Model}

The rivets model proposes that the ecological function of different species inhabiting a particular niche space overlaps, which means that even if a particular species with a definite functional trait is removed, it is simultaneously being replaced by another species with similar functional trait [22]. Overlapping of ecological function enables an ecosystem to persist because it enables in compensating of the desired functions by another species if any of the species present in an ecosystem is being removed. Rivets model presumes that ecological functional space is relatively small. Therefore, as species are added to an ecosystem, their functions begin to overlap or complement one another. This overlap allows ecological function to persist despite the loss of a limited number of species, since species with similar functions can compensate for the elimination or decline of other species. In ecological function, the loss of a single species from an ecological function space does not necessarily degrade the ecological function as the function carried out by the latter will be compensated by the other existing species with the similar function. But loss of several species with the similar functional trait will result in the degradation of the ecological function because there will be no left out species in the niche space which can compensate the functions carried out by the latter species.

\subsection{Idiosyncratic Model}

Idiosyncratic in ecology means that each species inhabiting a niche is ecologically different from one another. The idiosyncratic model proposed by Lawton [43] suggests that ecological function of a particular niche varies idiosyncratically or proportionately as species richness increases. This model argues that the contribution of each species towards ecological function is potentially influenced by the interactions among species. Therefore, the effects of addition or removal of species depends entirely on the nature of the species introduced or removed and also with the nature of the species with which it interacts. Interaction among species is highly essential for proper functioning of the ecosystem. Most of the important biological phenomenon in an ecosystem successfully occurs due to interaction and involvement of diverse organisms. The higher is the species interaction in an ecosystem indicates higher species richness of the particular ecosystem. The higher the species richness, the more is the ecosystem stability and finally the more will be the ecosystem productivity. Suppose an ecosystem contains few of the microorganisms carrying out the biological processes of nitrogen fixation and phosphate solubilisation. These functions indicate the functioning of the particular ecosystem. On further addition of new microbial cells to the latter, the species richness will increase which will automatically increase the rate of ecological functions going on in 
the ecosystem. Thus it can be said that the idiosyncratic model positively correlates ecological function with species richness.

\section{Statistical Analysis of Functional Diversity}

Functional diversity is a function of the species abundances in the community. The functional diversity of an ecosystem is measured by use of indices. Diversity index is a mathematical measure of species diversity in a given community. Diversity indices provide more information about community composition than simply species richness (i.e., the number of species present). They also take the relative abundances of different species into account. A diversity index depends not only on species richness but also on the evenness, or equitability, with which individuals are distributed among the different species.

The two commonly used indices for measurement of species diversity are as follows.

\subsection{Simpson Index}

Simpson's diversity index $(D)$ is a simple mathematical measure that characterizes species diversity in a community. In ecology, it is often used to quantify the biodiversity of a habitat. It takes into account the number of species present, as well as the abundance of each species [44] [45]. Simpson Index $(D)$ measures the probability that two individuals selected randomly from a sample will belong to the same species (or some category other than species). The value of $D$ ranges from 0 and 1. In Simpson's index, 0 represents infinity and 1 represents zero diversity [46]. This is neither intuitive nor logical. So in order to avoid this problem Simpson's Index of Diversity has been calculated.

\subsubsection{Simpson's Index of Diversity (1-D)}

The value of Simpson's Index of Diversity ranges between 0 and 1. The higher the Simpson's index value the greater will be the diversity. This index represents the probability that two individuals selected randomly from a sample will belong to two different species [45] [47].

\subsubsection{Simpson's Reciprocal Index $(1 / D)$}

The value of this index starts with 1 as the lowest possible figure. This figure would represent a community having only one species. The higher the value the greater is the diversity of the ecosystem [45] [48].

\subsection{Shannon Index}

This index is determined by both the number of species and the even distribution of individuals among those species. This means the Shannon index takes into account both the species richness as well as species evenness of an ecosystem. It indicates the degree of uncertainty of predicting the species of a given individual picked at random from the community [49]. The Shannon weaver index varies proportionately with the diversity of the ecosystem [50]. The values of Shannon index generally varies in between 1.5 and 3.5 in most of the ecological studies. The Shannon index increases as both the richness and the evenness of the community increase. This index incorporates 
both the significant components of an ecosystem to measure functional diversity of an ecosystem. This can prove to be advantageous as well as disadvantageous in fact. It can be advantageous because both the components that rule the ecosystem are being taken into account but at the same time it can prove to be disadvantageous because any change in any one of the component will bring about change in the diversity index value. It is strength because it provides a simple, synthetic summary, but it is a weakness because it makes it difficult to compare communities that differ greatly in richness.

\section{Conclusion}

Functional diversity is a measure of the value and range of functional traits prevailing in an ecosystem. It is an important biological key to access the functioning of an ecosystem. Any misbalance in the functional diversity of an ecosystem threatens the productivity and stability of the ecosystem. Functional diversity can be used as a measuring index for quantifying the stability of an ecosystem which is an important aspect of an active and highly productive ecosystem. A biologically stable ecosystem shows high resistance to disturbances and hence, shows high productivity in comparison with a less stable ecosystem. So it can be said that an ecosystem with high functional diversity will exhibit diverse biological activities. Thus, it can be considered that an ecosystem showing higher functional diversity is capable of executing diverse biological activities right from a healthy agriculture to ecosystem bioremediation. To this end, functional diversity can be considered as an efficient indicator of ecosystem screening.

\section{Acknowledgements}

The authors would like to thank Dr. Shaon Ray Chaudhuril for her valuable contributions for the improvement of the manuscript. This work is fully supported by a grant in aid from the Assam Science Technology \& Environment Council (ASTEC) (Department of Science and Technology, Govt. of Assam, India) (Sanction Number: ASTEC/S $\& \mathrm{~T} / 192(157) / 2015-2016 / 3933)$.

\section{Conflict of Interest}

The authors declare no conflict of interest.

\section{References}

[1] Diaz, S. and Cabido, M. (2001) Vive la différence: Plant Functional Diversity Matters to Ecosystem Processes. Trends in Ecology and Evolution, 16, 646-655. https://doi.org/10.1016/S0169-5347(01)02283-2

[2] Petchey, O.L. and Gaston, K.J. (2006) Functional Diversity: Back to Basics and Looking forward. Ecology Letters, 9, 741-758. https://doi.org/10.1111/j.1461-0248.2006.00924.x

[3] Tilman, D. (1999) The Ecological Consequences of Changes in Biodiversity: A Search for General Principles. Ecology, 80, 1455-1474. https://doi.org/10.2307/176540

[4] Stotzky, G. (1997) Soil as an Environment for Microbial Life. In: van Elsas, J.D., Trevors, J.T. and Wellington, E.M.H., Eds., Modern Soil Microbiology, Marcel Dekker, New York, $1-20$.

[5] Pietramellara, G., Ascher, J., Ceccherini, M.T. and Renella, G. (2002) Soil as a Biological System. Annals of Microbiology, 52, 119-132. 
[6] Nannipieri, P., Ascher, J., Ceccherini, M., Landi, L., Pietramellara, G. and Renella, G. (2003) Microbial Diversity and Soil Functions. European Journal of Soil Science, 54, 655-670. https://doi.org/10.1046/j.1351-0754.2003.0556.x

[7] Pettersson, M. and Baath, E. (2003) Temperature-Dependent Changes in the Soil Bacterial Community in Limed and Unlimed Soil. FEMS Microbiology Ecology, 45, 13-21. https://doi.org/10.1016/S0168-6496(03)00106-5

[8] Lauber, C.L., Hamady, M., Knight, R. and Fierer, N. (2009) Pyrosequencing-Based Assessment of Soil pH as a Predictor of Soil Bacterial Community Structure at the Continental Scale. Applied and Environmental Microbiology, 75, 5111-5120. https://doi.org/10.1128/AEM.00335-09

[9] Mason, N.W.H., Mouillot, D., Lee, W.G. and Wilson, J.B. (2005) Functional Richness, Functional Evenness and Functional Divergence: The Primary Components of Functional Diversity. Oikos, 111, 112-118. https://doi.org/10.1111/j.0030-1299.2005.13886.x

[10] Villeger, S., Mason, N.W.H. and Mouillot, D. (2008) New Multidimensional Functional Diversity Indices for a Multifaceted Framework in Functional Ecology. Ecology, 89, 22902301. https://doi.org/10.1890/07-1206.1

[11] Mouillot, D., Mason, W.H.N., Dumay, O. and Wilson, J.B. (2005) Functional Regularity: A Neglected Aspect of Functional Diversity. Oecologia, 142, 353-359. https://doi.org/10.1007/s00442-004-1744-7

[12] Schleuter, D., Daufresne, M., Massol, F. and Argillier, C. (2010) A User's Guide to Functional Diversity Indices. Ecological Monographs, 80, 469-484. https://doi.org/10.1890/08-2225.1

[13] Petchey, O.L. (2003) Integrating Methods That Investigate How Complementarily Influences Ecosystem Functioning. Oikos, 101, 323-330. https://doi.org/10.1034/j.1600-0706.2003.11828.x

[14] Tilman, D., Weldin, D. and Knops, J. (1996) Productivity and Sustainability Influenced by Biodiversity in Grasslands Ecosystems. Nature, 379, 718-720. https://doi.org/10.1038/379718a0

[15] Naeem, S. (2002) Disentangling the Impacts of Diversity on Ecosystem Functioning in Combinatorial Experiments. Ecology, 83, 2925-2935. https://doi.org/10.1890/0012-9658(2002)083[2925:DTIODO]2.0.CO;2

[16] Kleinebecker, T., Hoelzel, N. and Vogel, A. (2010) Patterns and Gradients of Diversity in South Patagonian Ombrotrophic Peat Bogs. Austral Ecology, 35, 1-12. https://doi.org/10.1111/j.1442-9993.2009.02003.x

[17] Wang, C., Long, R., Wang, Q., Liu, W., Jing, Z. and Zhang, L. (2010) Fertilization and Litter Effects on the Functional Group Biomass, Species Diversity of Plants, Microbial Biomass and Enzyme Activity of Two Alpine Meadow Communities. Plant and Soil, 331, 377-389. https://doi.org/10.1007/s11104-009-0259-8

[18] Keddy, P.A. (1992) A Pragmatic Approach to Functional Ecology. Functional Ecology, 6, 621-626. https://doi.org/10.2307/2389954

[19] Kleidon, A., Adams, J., Pavlick, R. and Reu, B. (2009) Simulated Geographic Variations of Plant Species Richness, Evenness and Abundance Using Climatic Constraints on Plant Functional Diversity. Environmental Research Letters, 4, Article ID: 014007. https://doi.org/10.1088/1748-9326/4/1/014007

[20] Pausas, J.G. and Austin, M.P. (2001) Patterns of Plant Species Richness in Relation to Different Environments: An Appraisal. Journal of Vegetation Science, 12, 153-166. https://doi.org/10.2307/3236601

[21] Grover, J.P. (1997) Resource Competition. Springer, Berlin. https://doi.org/10.1007/978-1-4615-6397-6 
[22] Ehrlich, P.R. and Ehrlich, A.H. (1981) Extinction: The Causes and Consequences of the Disappearance of Species. Random House, New York, 72-98.

[23] Walker, B.H. (1992) Biodiversity and Ecological Redundancy. Conservation Biology, 6, 1823. https://doi.org/10.1046/j.1523-1739.1992.610018.x

[24] Lawton, J.H. and Brown, V.K. (1993) Redundancy in Ecosystems. In: Schulze, E.D. and Mooney, H.A., Eds., Biodiversity and Ecosystem Function, Springer, Berlin, 255-270.

[25] Carpenter, S.R. (1996) Drivers and Dynamics of Changes in Biodiversity. United Nations Environment Programme (UNEP), Global Biodiversity Assessment, Cambridge University Press, Cambridge, 311-318.

[26] Naeem, S. (1998) Species Redundancy and Ecosystem Reliability. Conservation Biology, 12, 39-45. https://doi.org/10.1046/j.1523-1739.1998.96379.x

[27] Tilman, D. (2001) Functional Diversity. Encyclopedia of Biodiversity, 3, 109-120. https://doi.org/10.1006/rwbd.1999.0154

[28] Alder, P.B. and Bradford, J.B. (2002) Compensation: An Alternative Method for Analyzing Diversity-Productivity Experiments. Oikos, 96, 411-420. https://doi.org/10.1034/j.1600-0706.2002.960303.x

[29] Tilman, D. (1997) Distinguishing between the Effects of Species Diversity and Species Composition. Oikos, 80, 185. https://doi.org/10.2307/3546532

[30] Fridley, J.D. (2001) The Influence of Species Diversity on Ecosystem Productivity: How, Where and Why? Oikos, 93, 514-526. https://doi.org/10.1034/j.1600-0706.2001.930318.x

[31] Kahmen, A., Renker, C., Unsicker, S.B. and Buchmann, N. (2006) Niche Complementarity for Nitrogen: An Explanation for the Biodiversity and Ecosystem Functioning Relationship? Ecology, 87, 1244-1255. https://doi.org/10.1890/0012-9658(2006)87[1244:NCFNAE]2.0.CO;2

[32] Chapin, F.S., Schulze, E.D. and Mooney, H.A. (1990) The Ecology and Economics of Storage in Plants. Annual Review of Ecology and Systematics, 21, 423-447. https://doi.org/10.1146/annurev.es.21.110190.002231

[33] Spehn, E.M., Scherer-Lorenzen, M., Schmid, B., Hector, A., Caldeira, M.C., Dimitrakopoulos, P.G., Finn, J.A., Jumpponen, A., O’donnovan, G., Pereira, J.S. and Schulze, E.D. (2002) The Role of Legumes as a Component of Biodiversity in a Cross-European Study of Grassland Biomass Nitrogen. Oikos, 98, 205-218. https://doi.org/10.1034/j.1600-0706.2002.980203.x

[34] Scherer-Lorenzen, M., Palmborg, C., Prinz, A. and Schulze, E.D. (2003) The Role of Plant Diversity and Composition for Nitrate Leaching in Grasslands. Ecology, 84, 1539-1552. https://doi.org/10.1890/0012-9658(2003)084[1539:TROPDA]2.0.CO;2

[35] Di Castri, F. and Younes, T. (1990) Fonction de la diversite biologique au sien de l' eosysteme. Acta Oecologica, 11, 429-444.

[36] Walker, B. (1995) Conserving Biological Diversity through Ecosystem Resilience. Conservation Biology, 9, 747-752. https://doi.org/10.1046/j.1523-1739.1995.09040747.x

[37] Franklin, J.F. (1993) Preserving Biodiversity: Species, Ecosystems or Landscapes? Ecological Applications, 3, 202-205. https://doi.org/10.2307/1941820

[38] Vitousek, P.M. and Hooper, D.U. (1993) Biological Diversity and Terrestrial Ecosystem Biogeochemistry. In: Schulze, E.-D. and Mooney, H.A., Eds., Biodiversity and Ecosystem Function, Springer, Berlin, 3-14.

[39] Gitay, H., Wilson, J.B. and Lee, W.G. (1996) Species Redundancy: A Redundant Concept? Journal of Ecology, 84, 121-124. https://doi.org/10.2307/2261706

[40] Darwin, C. (1859) On the Origin of the Species by Natural Selection.

[41] MacArthur, R. (1955) Fluctuations of Animal Populations and a Measure of Community 
Stability. Ecology, 36, 533-536. https://doi.org/10.2307/1929601

[42] May, R.M. (1973) Stability and Complexity in Model Ecosystems. Princeton University Press, Princeton, 6.

[43] Lawton, J.H. (1994) What Do Species Do in Ecosystems? Oikos, 71, 367-374. https://doi.org/10.2307/3545824

[44] Simpson, E.H. (1949) Measurement of Diversity. Nature, 163, 688. https://doi.org/10.1038/163688a0

[45] Bentoa, F.M., de Oliveira Camargoa, F.A., Okeke, B.C. and Frankenberger, W.T. (2005) Diversity of Biosurfactant Producing Microorganisms Isolated from Soils Contaminated with Diesel Oil. Microbiological Research, 160, 249-255. https://doi.org/10.1016/j.micres.2004.08.005

[46] Magurran, A.E. (1988) Ecological Diversity and Its Measurement. Springer, Berlin. https://doi.org/10.1007/978-94-015-7358-0

[47] Zhou, J., Xia, B., Treves, D.S., Wu, L.Y., Marsh, T.L., O’Neill, R.V., Palumbo, A.V. and Tiedje, J.M. (2002) Spatial and Resource Factors Influencing High Microbial Diversity in Soil. Applied and Environmental Microbiology, 68, 326-334. https://doi.org/10.1128/AEM.68.1.326-334.2002

[48] Begon, M., Harper, J.L. and Townsend, C.R. (1996) Ecology. Blackwell Science, Oxford.

[49] Shannon, C.E. and Weaver, W. (1949) The Mathematical Theory of Communication Urbana.

[50] Teng, Y., Luo, Y., Sun, M., Liu, Z., Li, Z. and Christie, P. (2010) Effect of Bioaugmentation by Paracoccus sp. Strain HPD-2 on the Soil Microbial Community and Removal of Polycyclic Aromatic Hydrocarbons from an Aged Contaminated Soil. Bioresource Technology, 101, 3437-3443. https://doi.org/10.1016/j.biortech.2009.12.088

\section{Submit or recommend next manuscript to SCIRP and we will provide best service for you:}

Accepting pre-submission inquiries through Email, Facebook, LinkedIn, Twitter, etc. A wide selection of journals (inclusive of 9 subjects, more than 200 journals)

Providing 24-hour high-quality service

User-friendly online submission system

Fair and swift peer-review system

Efficient typesetting and proofreading procedure

Display of the result of downloads and visits, as well as the number of cited articles Maximum dissemination of your research work

Submit your manuscript at: http://papersubmission.scirp.org/

Or contact aim@scirp.org 